\title{
Simulation of Water Pollution Diffusion Based on WebGIS
}

\author{
Tianqi Kuang, Jinglong Du, Weiwei Zhang \\ School Environmental Science and Engineering, Suzhou University of Science and Technology, Suzhou, China \\ Email: jwuyue@163.com
}

How to cite this paper: Kuang, T.Q., Du, J.L. and Zhang, W.W. (2019) Simulation of Water Pollution Diffusion Based on WebGIS. Journal of Computer and Communications, 7, 28-38. https://doi.org/10.4236/jcc.2019.77004

Received: May 16, 2019

Accepted: July 7, 2019

Published: July 10, 2019

\begin{abstract}
Taking Liyang City of Jiangsu Province as the research object, a water pollution accident diffusion simulation and analysis system, taking WebGIS as the core, was established by taking finite difference method to do the system dynamics water quality model solution. This paper introduces the construction process of the model, the integration of the model with GIS, the interactive application of the system and users and the visual dynamic expression of water pollution accidents. By combining the statistical analysis of the spatial and environmental database in the system, the scientific simulation of the temporal and spatial relationship of the development of water pollution accidents on the client side is realized and providing precise decision support for early warning and control of water pollution diffusion.
\end{abstract}

\section{Keywords}

WebGIS, Visualization Simulation, Finite Difference Method, Water Quality Model; Decision Analysis

\section{Research Background}

Water resources are not only the basic resources of social and economic development, but also the source of human life. However, in the past decade, due to the acceleration of industrialization and urbanization, sudden water pollution incidents have occurred frequently in China, seriously threatening the surface water ecosystem and urban water supply security. However, the water environment system is a complex dynamic evolution system, which continuously exchanges material and energy with outside world. By using the geographic information system (GIS) based on the geospatial database, this system not only completes the real-time query and analysis of water quality basics, but also realizes the visual expression of sudden water pollution accidents through its spatial 
display ability to illustrate the extent and scope of the accidents, making it easier to make a scientific quantitative assessment and prediction so as to achieve the role of water quality early warning and timely control of pollution.

The research on water pollution diffusion started early in developed countries. The STORET-COGENT (Storage and Retrieval Database System \& Construction Grants Evaluation and Network Tracking System) [1] water quality retrieval and assessment system was developed and perfected by the United States in 1964 as the internationally developed earliest large-scale water environment quality information management system. The system has the functions of water quality evaluation, synchronization, predictions and projections. It pioneers the combination of GIS and water quality control has great significance for water pollution management and control. In order to reduce the risk of sudden water pollution accidents in transnational basins, the Danube Accident Emergency Warning System (DAEWS) [2] has been put into use in nine countries of Danube Basin in Europe since 1997. After continuous optimization, the Danube Accident Emergency Warning System (DAEWS) can be used for early warning of water pollution accidents and monitoring of water quality and provides technical support to improve the decision-making process of sudden water pollution incidents. In order to realize the organic combination of GIS with water quality, water quantity and terrain in the river basin and a series of models, Water Resources Research Center of Dublin College, National University of Ireland, has developed the DSS.CWM decision support system [3] for water management in the river basin, providing the functions of inquiry and analysis of water quality and prevent the emergence of sudden water pollution accidents.

In the mid-1980s, China began to attach importance to water pollution accidents. In order to study and explore the impact of water environmental safety accidents on social economy, the Songliao River Basin Management Committee developed a water quality model and water environment information management system [4] for the main stream of Songhua River by using MIKE model technology and GIS technology to take one-dimensional simulation and prediction of water pollution in river. Dou Ming [5] and others, based on the accident-type water environmental pollution risk assessment system, carried out the research on Hanjiang River water quality early warning system in 2002 with computer simulation technology and realized the optimal dispatch and comprehensive management of water resource. Ma Hui [6] and other established WebGIS-based decision support systems for water pollution simulation under two-dimensional network geographic environment, realizing the seamless integration of water quality monitoring data and water environment quality simulation and prediction model.

In summary, under the new normal development of the Internet, the new subject Geographic Information System (GIS), which integrates geographic data processing, can integrate environmental management and ecological protection into the GIS system. By utilizing the efficient spatial analysis ability and powerful data display ability of GIS, it has injected new ideas into the traditional 
low-efficiency and high-cost water environmental protection work. However, the above water environment information management system still has many areas to be improved: it cannot simulate one-dimensional and two-dimensional water pollution accidents at the same time; the model has weak pertinence and strong limitations in application; the interface is complex or the model is obscure and difficult to popularize. Taking Liyang City of Jiangsu Province as an example, this paper chooses the finite difference water quality model which is most suitable for the hydrological characteristics of the basin, develops a surface water quality monitoring and water pollution diffusion analysis and simulation system suitable for county and municipal environmental protection applications, realizes the simulation visualization of the temporal and spatial distribution of sudden water pollution accidents in rivers and reservoirs and constitutes basic information, decision-making and human-computer interactions supporting the emergency treatment of sudden water pollution accidents scientifically, efficiently and accurately.

\section{Application of Mathematical Model in Water Quality Simulation}

\subsection{Introduction of Research Area}

The main watershed of Liyang is the Shahe Reservoir of Tianmu Lake and Daxi Reservoir and its tributaries. The Daxi Reservoir is located in the upper reaches of the Daxi River in the hilly area of the southwest of Liyang City. The Shahe Reservoir is composed of the Dasha River originating from Tianlu Mountain and the Fushi River originating from Xiafang Village. Both belong to the Tianmu Lake watershed of the Nanhe River system in the western part of the Taihu Lake Basin and are closely related to the ecological stability of the Taihu Basin.

The water quality in this area mainly was influenced by agricultural pollution caused by farming and livestock farming, with ammonia nitrogen and $\mathrm{P}$ as the main elements. Because it is located in the subtropical monsoon climate with abundant precipitation, these pollutants are discharged into reservoirs from paddy fields with irrigation, resulting in water eutrophication.

Therefore, combined with the hydrological characteristics and pollution source types of the study area, the system chooses a suitable water environment quality prediction model for the watershed to quantify the sudden water events in the area.

\subsection{Water Pollution Diffusion Analysis Model Based on Monitoring Data}

Based on system dynamics, this system establishes a dynamic simulation model of sudden water pollution diffusion simulation, which mainly includes system dynamics hydrodynamic model and water quality model and integrates the final calculation results with GIS system to realize the visualized dynamic expression of water pollution diffusion simulation. 


\subsubsection{One-Dimensional River Water Quality Model}

The one-dimensional water quality model is a relatively simple environmental water model. When rivers or lakes are polluted, this water pollution prediction model is often used when the difference between the concentration distribution of cross sections and the average concentration of cross sections is small. It mainly studies variations of pollutant concentration distribution along the river and the variations over time in each section. The one-dimensional model only considers the transportation and distribution characteristics of pollutant concentration and its diffusion parameters in the longitudinal direction, i.e., the flow direction (generally set as the $\mathrm{x}$-axis). When pollutants are transported along the river, not only the flow but also the self-purification of the river should be considered. The corresponding water quality model [7] [8] is as follows:

$$
\frac{\partial C}{\partial t}=E_{x} \frac{\partial^{2} C}{\partial x^{2}}-U_{x} \frac{\partial C}{\partial x}-K C
$$

Here, $C$ denotes the concentration of pollutants in rivers, $t$ denotes time, $E_{x}$ denotes the diffusion coefficient in the $X$ direction, $U_{X}$ denotes the average discharge, and $K$ denotes the decay rate coefficient of the pollutants.

Because the finite difference method allows for easy construction of the system dynamics model, the finite difference method is chosen to calculate the numerical difference of the model. Obtained by deduction and rearrangement:

$$
C_{i}^{j+1}=C_{i}^{j}+\left(E_{i} \frac{C_{i+1}^{j}+C_{i-1}^{j}}{\Delta x^{2}}+u_{i} \frac{C_{i}^{j}}{\Delta x}\right) \Delta t-\left(E_{i} \frac{2 C_{i}^{j}}{\Delta x^{2}}+u_{i} \frac{C_{i+1}^{j}}{\Delta x}+k_{i} C_{i}^{j}\right) \Delta t
$$

In the formula, $E_{i}$ is the longitudinal dispersion coefficient of section I; $u_{i}$ is the average velocity of section I; $k_{i}$ is the pollutant decay rate coefficient of section I; $\Delta x$ are steps in the $X$ direction; $\Delta t$ are the time steps; $i$ is the section I; and $j$ is the time, $j$.

From the formula, the concentration value at time $(j+1)$, section I can be calculated iteratively from the concentration value at time $j$, section $(i+1),(i-$ 1 ) and other parameters (diffusion coefficient $E_{p}$ average velocity $u_{p}$ time steps $\Delta t$, position steps $\Delta x$ and pollutant decay rate coefficient $k_{i}$ ).

\subsubsection{Two-Dimensional River Water Quality Model}

When pollutants enter the water body, it is impossible to achieve uniform concentration mixing of the whole section in a short time. When there are significant differences in both the vertical and horizontal directions, the one-dimensional model cannot meet the needs of the system and the two-dimensional simulation model should be used [9]. The basic form of the two-dimensional water quality model for rivers [7] [8] is as follows:

$$
\frac{\partial C}{\partial t}=E_{x} \frac{\partial^{2} C}{\partial x^{2}}+E_{y} \frac{\partial^{2} C}{\partial y^{2}}-U_{x} \frac{\partial C}{\partial x}-K C
$$

In the formula, the dispersion coefficients $E_{x}$ and $E_{y}$ are in the $x$ and $y$ directions, respectively. $U_{x}$ is the velocity component in the $X$ direction, and $K$ is the decay rate coefficient of the pollutants. Since the essence of the system dynamics 
model is a set of differential equations, the finite difference solution of the two-dimensional river water quality model is as follows:

$$
\begin{aligned}
C_{i, j}^{n+1}= & C_{i, j}^{n}+\left(\frac{E_{i, j}^{x} C_{i+1, j}^{n}+E_{i, j}^{x} C_{i-1, j}^{n}}{\Delta x^{2}}+\frac{E_{i, j}^{y} C_{i, j+1}^{n}+E_{i, j}^{y} C_{i, j-1}^{n}}{\Delta y^{2}}+\frac{u_{i, j} C_{i, j}^{n}}{\Delta x}\right) \Delta t \\
& -\left(\frac{2 E_{i, j}^{x} C_{i, j}^{n}}{\Delta x^{2}}+\frac{2 E_{i, j}^{y} C_{i, j}^{n}}{\Delta y^{2}}+\frac{u_{i, j} C_{i+1, j}^{n}}{\Delta x}+k_{i, j} C_{i, j}^{n}\right) \Delta t
\end{aligned}
$$

Here, $E_{i, j}^{x}$ is the longitudinal dispersion coefficient of the I and J sections, $E_{i, j}^{y}$ is the transverse dispersion coefficient of the I and J sections, $u_{i, j}$ is the average flow velocity of the I and J sections, and $k_{i, j}$ is the decay rate coefficient of pollutants in the I and J sections.

\section{Coupling and Visualization of Watershed Water Environment Quality Simulation and Prediction Model with GIS System}

In order to realize the space-time simulation and visualization of water pollution accidents, it is necessary to display the model calculation results in the browser with the help of webGIS so as to facilitate interaction with users. The research area is gridded in two-dimensional plane map by two programming languages: Java and JavaScript. Then the pollutant concentration in the grid is calculated by the above-mentioned water pollution diffusion analysis model. And then the grid is rendered dynamically according to the pollutant concentration and the display effect is enhanced to achieve accurate visualization. Specific implementation steps (Figure 1) and key codes (taking the two-dimensional system dynamics water quality model as an example) are as follows:

Detailed steps are as follows:

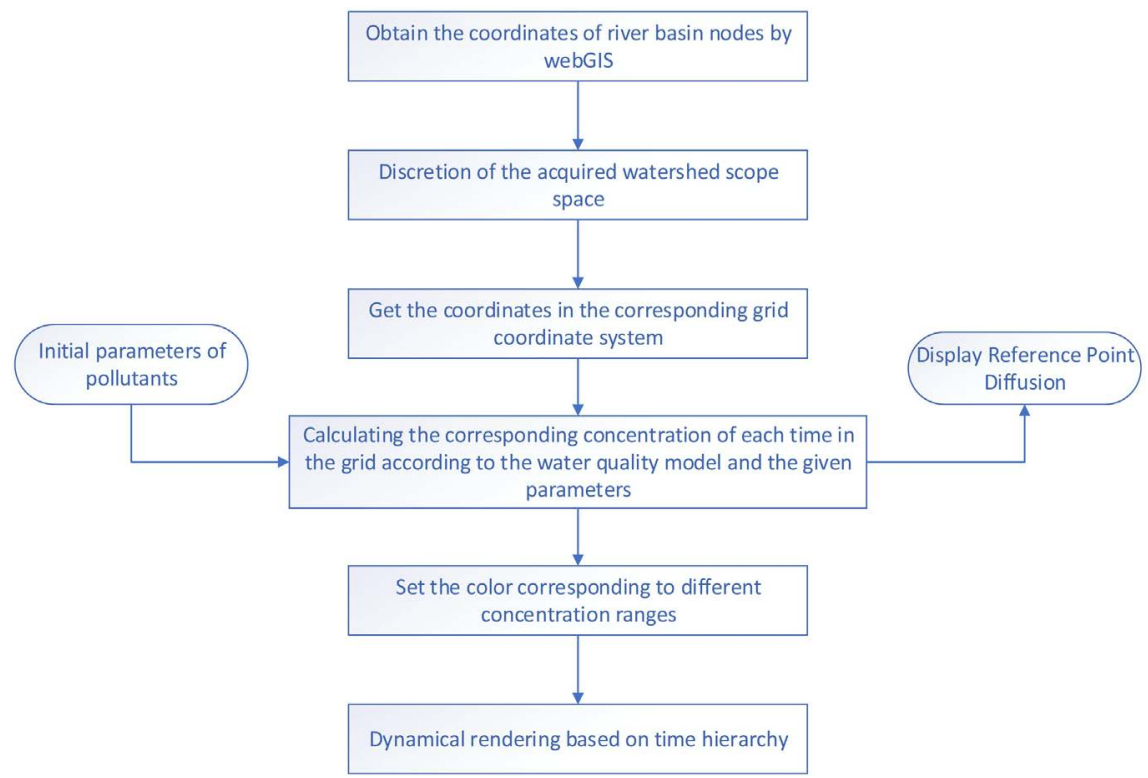

Figure 1. Flow chart of integration of watershed environment quality simulation and prediction model with GIS system. 
1) Obtaining the coordinates of river basin nodes by webGIS: divide the acquisition area into $10 \mathrm{~m}{ }^{\star} 10 \mathrm{~m}$ grid on average and get the coordinates of each grid in the corresponding coordinate system.

The geometric attributes of $x_{\min }$ and $y_{\min }$ of the corresponding watershed are accessed by webGIG. The cell grid with $10 \mathrm{~m}$ step length is assigned by for cycle, stored in the array in turn and the maximum outer rectangle of the watershed is obtained at the same time.

2) By setting the initial parameters for the model calculation under the simulated state, the pollutant concentration values at each time in each grid are obtained.

According to the arithmetic provided by the water model, the concentration of pollutants in each grid can be obtained by iteration of the concentration of pollutants in the preceding moment near the top, left, bottom and right of the grid.

3) In order to enhance the visualization of pollution diffusion, graded color settings were used to convert the water pollution concentration values into RGB true color images.

4) According to the set unit time, the dynamic effect of water pollution diffusion is generated.

\section{Examples of Water Pollution Accidents}

\subsection{Determination of Calculating Parameters of Water Quality Model}

Through the statistical analysis of the system spatial basic information database and environmental basic information database, the water quality status of each section can be grasped macroscopically and the main pollutant sources, flow rate and direction of the corresponding watershed can be analyzed so as to obtain more accurate initial parameters and simulate the diffusion process of water pollution accidents.

In addition, by using GIS, we can get the geographic coordinates of the incident site according to the place names and locations provided by the eyewitnesses and make full use of remote sensing technology to obtain water environment and water pollution information as an integrated information resource for the establishment and inspection of water pollution model [9].

\subsection{Input of Calculation Parameters of Water Quality Model}

When the user visits the browser, by specifying the pollution point source in the corresponding River basin and setting the initial state parameters such as the average flow velocity, the pollutant concentration of the pollution source, the diffusivity coefficient in all directions and the attenuation coefficient of the pollutant, the user can start the analysis and then calculate the concentration of each point iteratively through the above model. The client parameter setting interface is shown in Figure 2. 
River Pollution Concentration Analysis

Draw Start Analysis Stop Analysis Current Time: 0:00:00

Initial Parameter

Average Flow Rate: $0.5 \quad \mathrm{~m} / \mathrm{s}$

Concentration Of Pollution Source:

$0.028 \mathrm{mg} / \mathrm{l}$

Lateral Diffusion Coefficient: $4 \quad \mathrm{~m}^{2} / \mathrm{s}$

Pollutant Departure Time: $0.001 \quad \mathrm{~d}^{\wedge}-1$

Time limit: $\quad 3000$

Figure 2. User setting initial parameter interface for water diffusion simulation.

\subsection{Visualize Display of Water Pollution Accident Diffusion Client}

Visualization of water pollution accident diffusion will simulate the results of calculation after inputting the corresponding parameters in different time periods and realize the dynamic expression of the spatial distribution of pollutants at different time in each area of the client through the map layer released by ArcGIS Sever so as to realize the simulation of the whole process of water pollution accident and determine its diffusion range and impact degree (Figure 3 and Figure 4).

\subsection{Analysis of Pollutant Concentration Change}

The analysis of pollutant concentration change includes the analysis of pollution source concentration and pollution reference point concentration. It can analyze the trend of concentration change with time at the designated point and display in broken line graph (as shown in Figure 5 and Figure 6). By calculating the specific value of water pollution concentration corresponding to the region under the grid coordinate system, the specific situation of concentration change at each time can be accurately presented in the form of a data table (as shown in Figure 7).

\section{Conclusion}

This system takes Liyang water area of Jiangsu Province as the research object, adopts $\mathrm{B} / \mathrm{S}$ architecture, chooses the finite difference method which is more suitable for expressing its diffusion state according to the characteristics of the research area, couples the water quality model with the simulation and prediction model of water environment quality of the river basin and GIS, realizes the visual expression of one-dimensional and two-dimensional water quality mathematical models on the server side and can simulate space-time relationship of water pollution development of rivers and lakes respectively. Combining the attribute database of spatial geographic and environmental basic information and eyewitness feedback mechanism, we can analyze and summarize the initial parameters which are most in line with the real-time state of the study area, accurately simulate and control the water pollution diffusion and timely establish 


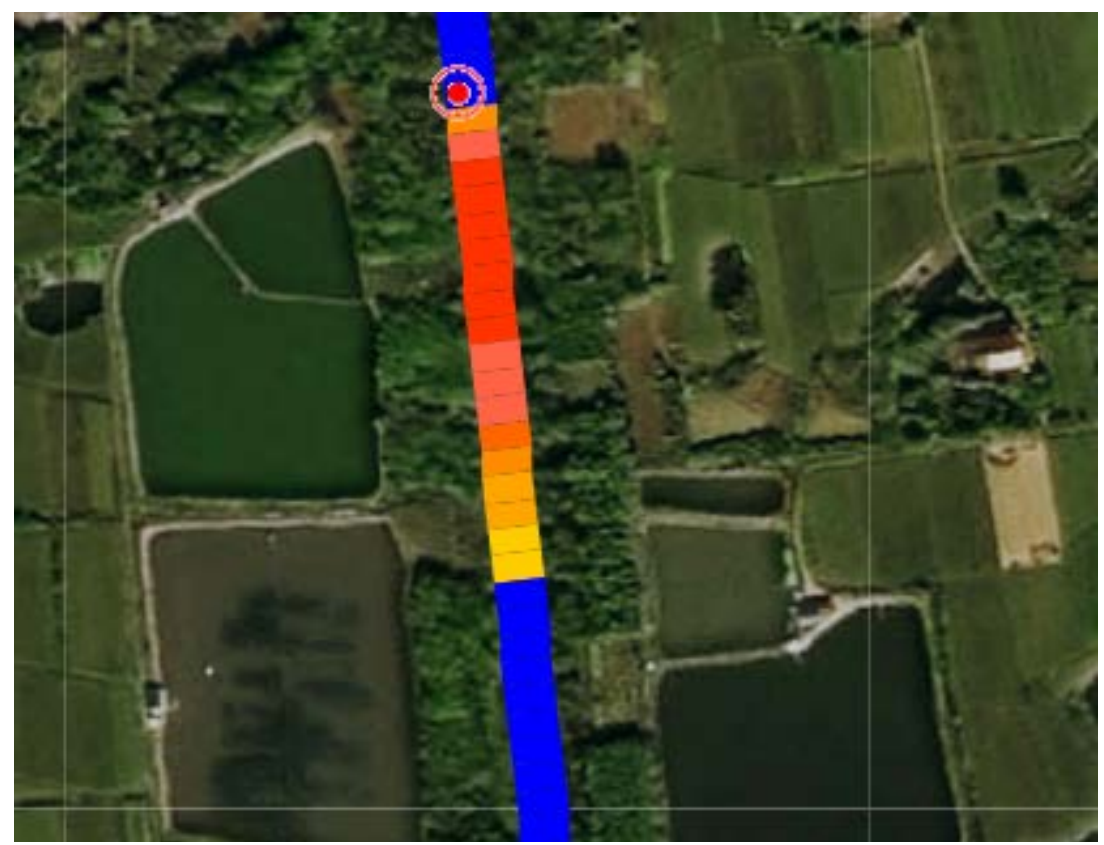

Figure 3. Diffusion of river water pollution accidents at specific times.

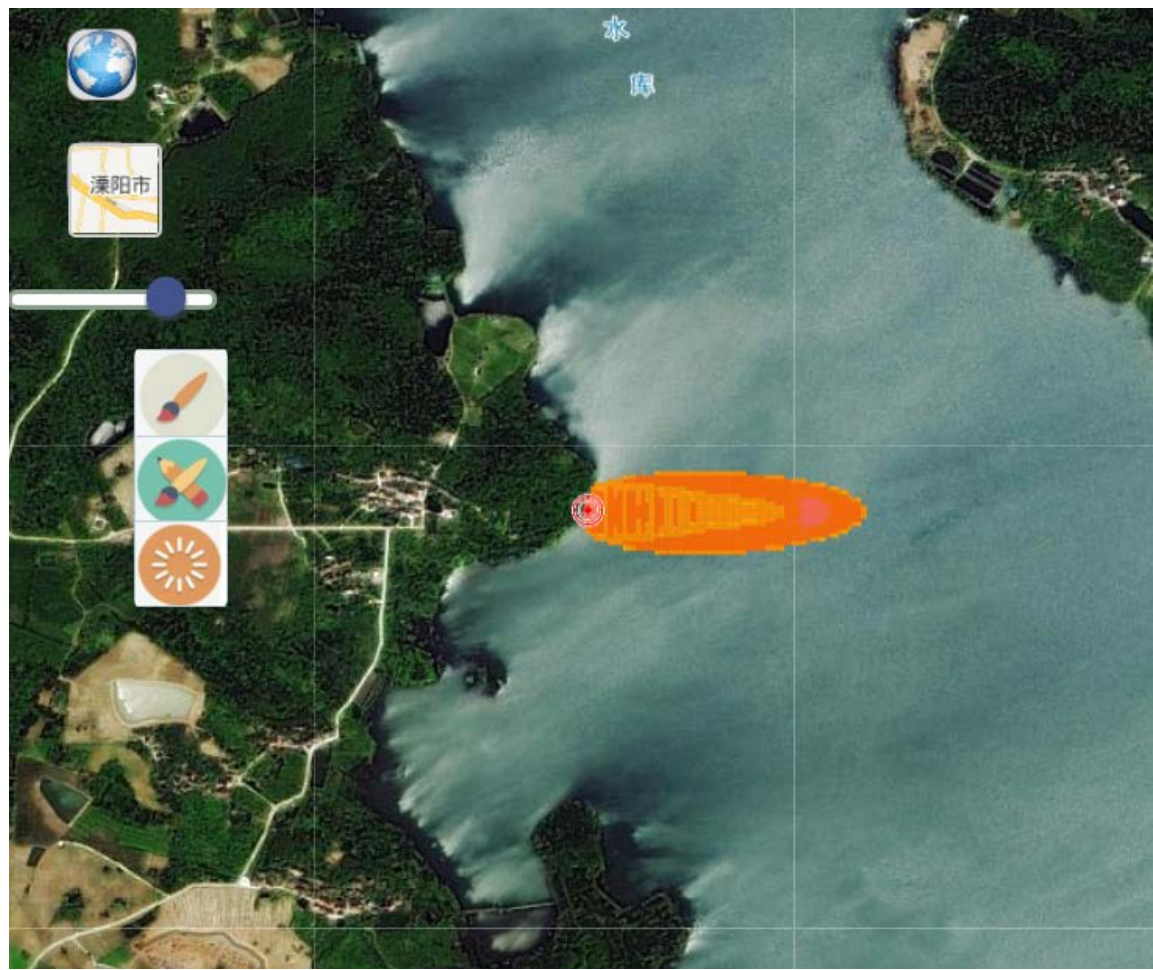

Figure 4. Diffusion of water pollution accidents in reservoirs at specific times.

the spatial relationship between the pollution source and the object of water environmental protection. The model provides decision support for the early warning and control of water pollution diffusion, effectively improving the efficiency of pollution control and making the integrated management of water environment more precise and quantitative. 


$$
\text { Start Analysis Current Time: 0:00:00 (D) Time v Draw }
$$

Concentration Change With Time

Concentration $(\mathrm{mg} / \mathrm{L})$

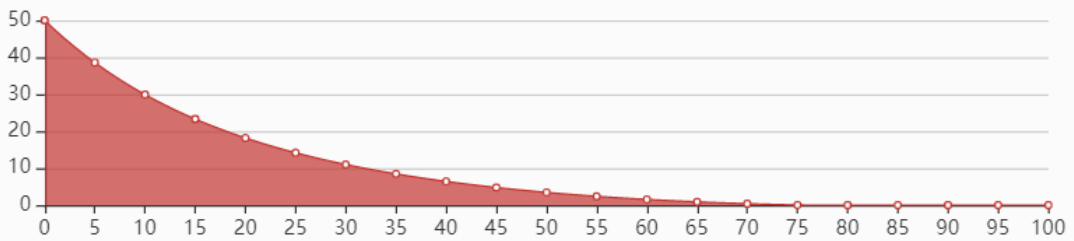

\section{1}

Section Statistics

Initial Parameter

Average Flow Rate: $0.5 \quad \mathrm{~m} / \mathrm{s}$

Concentration Of Pollution Source:

$50 \quad \mathrm{mg} / \mathrm{l}$

Lateral Diffusion Coefficient: $3 \quad \mathrm{~m}^{2} / \mathrm{s}$

Longitudinal Diffusion Coefficient:

$2 \mathrm{~m}^{2} / \mathrm{s}$

Pollutant attenuation coefficient: 0.001
Diffusion Situation

Contaminant Arrival Time:

Peak Concentration Of Pollutants: $\mathrm{mg} / \mathrm{L}$

Contaminant arrival time:

Pollutant departure time:

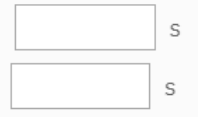

Distance Between Contaminant And

Source Point : $\mathrm{m}$

Figure 5. Change of pollution source concentration in reservoir pollution accident.

Concentration Analysis Of Pollution Sources

Start Analysis Current Time: 0:00:00 (1) Time v Draw

\section{Concentration Change With Time}

Concentration(mg/L)
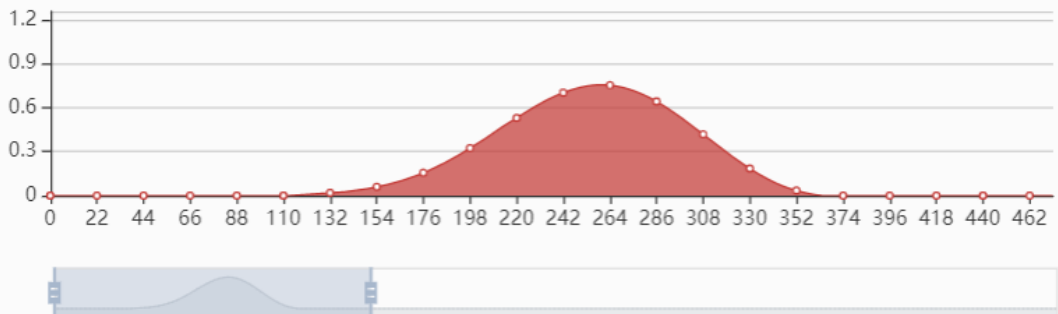

Section Statistics

Initial Parameter

Average Flow Rate: $0.5 \mathrm{~m} / \mathrm{s}$

Concentration Of Pollution Source:

$50 \quad \mathrm{mg} / \mathrm{l}$

Lateral Diffusion Coefficient: $3 \quad \mathrm{~m}^{2} / \mathrm{s}$

Longitudinal Diffusion Coefficient:

$2 \quad \mathrm{~m}^{2} / \mathrm{s}$

Pollutant attenuation coefficient: 0.001
Diffusion Situation

Contaminant Arrival Time: 114

Peak Concentration Of Pollutants:

$0.756 \quad \mathrm{mg} / \mathrm{L}$

Contaminant arrival time: 259

Pollutant departure time: 363

Distance Between Contaminant And

Source Point : 117 m

Figure 6. Concentration changes at designated point of reservoir pollution accidents. 


\begin{tabular}{|c|c|c|}
\hline \multicolumn{2}{|c|}{ Contaminant Concentration Table } \\
\hline Ascending & Descending & Export Excel \\
\hline Number & Time/s & Concentration \\
\hline 1 & 0 & 20.0000 \\
\hline 2 & 1 & 19.3800 \\
3 & 2 & 18.7712 \\
4 & 3 & 18.1738 \\
5 & 4 & 17.5879 \\
6 & 5 & 17.0136 \\
7 & 6 & 16.4509 \\
8 & 7 & 15.9001 \\
9 & 8 & 15.3610 \\
\hline 10 & 9 & 14.8338 \\
\hline 11 & 10 & 14.3184 \\
12 & 11 & 13.8149 \\
13 & 12 & 13.3232 \\
\hline «Previous & Next » & \\
\hline
\end{tabular}

Figure 7. Concentration changes at designated points of river pollution accidents.

\section{Acknowledgements}

At the end of this paper, I would first like to thank my tutor, Professor Du Jinglong, for his careful guidance and strict requirements, which enabled me to overcome the difficulties and finally complete the research task. Mr. Du's noble personality, meticulous academic attitude, inspired me in the spirit of my work, gave me the motivation to continue to work hard on the road of scientific research.

In addition, I would also like to thank my team members, Li Wei and Wan Genyi, for their great help and encouragement during the study. We have jointly optimized the implementation of complex water quality model algorithms through the exchange discussion process and improved system operating efficiency.

Secondly, I would also like to thank the project fund: Changzhou Social Development Project "Study of County (City) Level Intelligent Environmental Information Platform-Taking Fuyang City as an Example" to provide data and financial support.

Finally, I am especially grateful to my parents, who taught me to be a human being, often spurred and encouraged me, and silently supported me to complete the research.

\section{Conflicts of Interest}

The authors declare no conflicts of interest regarding the publication of this paper. 


\section{References}

[1] Yang, H. and Yang, S. (2003) Application of River Comprehensive Water Quality Model QUAL2E in River Simulation. Yunnan Environmental Science, 22, 22-25.

[2] Botterweg, T. and Rodda, D.W. (1999) Danube River Basin: Progress with the Environmental Programme. Water Science and Technology, 40, 1-8.

https://doi.org/10.2166/wst.1999.0495

[3] Loos, R., Locoro, G., Comera, S., et al. (2010) Pan-European Survey on the Occurrence of Selected Polar Organic Persistent Pollutants in Ground Water. Water Research, 44, 4115-4126. https://doi.org/10.1016/j.watres.2010.05.032

[4] Li, Z., Wang, H., Jin, C., et al. (2007) Songhua River Mainstream Water Quality Model and Water Environment Management Information System Technical Report. Songliao River Basin Water Resources Protection Bureau, Changchun.

[5] Dou, M., Li, C. and Wang, T. (2005) Research on Hanjiang Water Quality Warning System. People's Yangtze River, 11, 38-40.

[6] Ma, H., Shen, S.H. and Chen, Y.Q. (2016) Research on Water Pollution Simulation Analysis System Based on Dynamic Real-Time Monitoring Data. Journal of Yangtze River Scientific Research Institute, 33, 54-58.

[7] Zhang, B. and Wang, Q. (2007) Research and Application of Dynamic Model of Water Quality Simulation System for Water Pollution Accident Based on GIS. Institute of Remote Sensing Applications, Chinese Academy of Sciences.

[8] Zhang, B. and Wang, Q. (2015) Space-Time Simulation and Visual Control of Water Pollution Accidents. China Environmental Science Press, Beijing.

[9] Ding, X., Xu, J., Yao, Q., et al. (2003) Space-Time Simulation of Water Pollution Emergencies Integrated with GIS and Digital-Analog. Journal of Hohai University: Natural Science Edition, 31, 203-206. 